DOI: $10.20472 / S S .2016 .5 .1 .005$

\title{
COMPARISON OF PARAMETRIC AND NONPARAMETRIC MODELING: AESTHETIC EFFECT OF KAMRAN KHAVARANI'S PAINTINGS
}

\section{SIMIN MOZAYENI, PARISA AMIRMOSTOFIAN}

\begin{abstract}
:
This research is an extension of Amirmostofian, Mozayeni (2016). Our hypothesis is that Khavarani's painting style, Abstract Romanticism, combines artistic elements that impart positive effect on viewers' psyche. Our data encompass 320 surveys. Previously, we reported three nonparametric tests results, and concluded that Khavarani's paintings have positive effects on viewers' psyche. In this research we examine new results for six Multivariate General Linear Model (MGLM) estimations for six Khavarani's groups. With their R2, 0.04-021, and negligible and insignificant coefficients for variables Age, Gender, and the base mood, we propose that Khavarani's paintings influence the subjects' Mood After, the dependent variable in our model. We invoke Vartanian and Skov (2014), and recognize that subjects in the six groups experienced a meditative joy.
\end{abstract}

\section{Keywords:}

Models Evaluation, Validation and Selection, Khavarani, Abstract Romanticism, Meditative Effect of Painting, Behavioral Economics

JEL Classification: C10, C52, Z11

\section{Authors:}

SIMIN MOZAYENI, State University of New York at New Paltz, USA, Email: mozayens@newpaltz.edu PARISA AMIRMOSTOFIAN, None, USA, Email: parisa@parisaarttherapy.com

\section{Citation:}

SIMIN MOZAYENI, PARISA AMIRMOSTOFIAN (2016). Comparison of Parametric and Nonparametric Modeling: Aesthetic Effect of Kamran Khavarani's Paintings. International Journal of Social Sciences, Vol. V(1), pp. 72-92., 10.20472/SS.2016.5.1.005

Contributions:

(1) Mozayeni: Literature Review, design of data subgroups, verification of raw and coded data, statistical methodology and execution, interpretation of data, drafting the manuscript and its revisions, journal submission and follow-up work. (2) Amirmostofian: The initial research question, conception and design of the data, acquisition of data, coding and entry of data, review and approval of manuscript drafts.

Acknowledgments: 
(1) We acknowledge competent and dedicated research assistance of Ms. Rui Wang, a Senior Economics major (2014-15) at the State University of New York at New Paltz. Under supervision of Prof. Mozayeni, she conducted estimation of the models for this research. (2) We also acknowledge research support from Dr. Einat Metzl, Associate Professor of Art Therapy, and the Chair of the Alumni Research Advising Committee (2013-14) at Loyola Marymount University in Los Angles, California. We have benefitted from her advice for the design of the material, procedure and the survey questionnaire. In addition, she guided the direction of the research question in the early stages of our research.

Statement of Conflict of Interest:

The authors have NO affiliations with or involvement in any organization or entity with any financial interest (such as honoraria; educational grants; participation in speakers' bureaus; membership, employment, consultancies, stock ownership, or other equity interest; and expert testimony or patent-licensing arrangements), or nonfinancial interest (i.e., professional relationships, affiliations, knowledge or beliefs) in the subject matter or materials discussed in this manuscript. 


\section{Introduction}

This research is an extension of Amirmostofian and Mozayeni (2016, forthcoming). Inevitably, our data and Literature Review are mostly the same. However, our methodology is completely different. In the previous research we used nonparametric models of Freidman, Mann-Whitney and Kruskal-Wallis. In this research we apply the parametric Multivariate General Linear Model (MGLM) to assess the effect of Khavarani's painting on subjects mind. Therefore, we are able to extract more information from our data, pertaining to subjects' base mood, age, gender and these variables' collective effect on subjects' mood after-after viewing paintings. As before, we verify that Khavarani's painting style, known as Abstract Romanticism, combines artistic elements that impart positive effect on individuals' psyche, thus their mood. The Likert Scale data are coded in numbers. As we noted in our first research, our motivation for this research is multi-dimensional. First, we had firsthand observation of the effect of Khavarani's paintings on enhancement of "mood" for several years. Second, we were provoked by numerous testimonials by viewers of his paintings over a decade long. Third, Boime's (2008) proposition that Khavarani's painting style has artistic characteristics that impart positive effect on individual's mind begged for an empirical research. In addition to those considerations in our first report, we also aim at comparing the general results we produce from the parametric model to the ones from the nonparametric models. In these contexts and the Aesthetical literature, we pursue our research agenda.

The importance of the effect of visual arts on the human brain has been for long the subject of inquiries in psychobiology, social psychology, neurology, and more recently in neurasthenics. Numerous studies have examined the aesthetic effects of color, shape and lighting in space design on the human psyche. Several have specifically evaluated the effect of paintings on the human brain.

We reiterate that the Literature Review here is mostly as we presented in Amirmostofian and Mozayeni (2016). Therefore, we note again that the related literature generally falls on two distinct tracks, namely, theoretical or empirical. A few have formulated their empirical observations to develop the theory of beauty and aesthetics. Irrespective of their focus and methodology, they amass strong evidence that visual arts stimulate the brain and affect viewers' psyche, and thus their mood. We review both the theoretical and empirical aesthetic literature, which have mostly emerged in the last 10 years, almost in parallel. Although, the advent of fMRI technology has facilitated direct observation of the effect of art stimuli on the human brain, the survey method has eased the research administratively and economically. According to the joint study by Johns Hopkins' Brain and Mind Center and the Walter Museum, noted in Vikan (2010), these two methods produce "identical" results. Their finding unifies the two method of empirical research. 
The old and new notable theoretical works in aesthetics include: Tolstoi (1897-98], Berlyne (1965, 1971 and 1974), Ramachandran and Hirtstein (1999), Zeki (1999), Solso (2003), Reber and Schawarz (2004), Silvia (2005), Anjan and Vartanian (2011), Ishuzi and Zeki [2011], Gopnikc (2012), Hager and associates (2012), Kendal (2012), Vartanian and Skov (2014), among others.

Major empirical works in aesthetics over the last decade include: Cela-Conde (2004), Kemp and Cupchick [2007], Silvia [2007], a joint study by the Johns Hopkins Brain and Mind Center with Walter Museum (2010), Lacey and associates (2011), Tsuklura and Gabeza (2011), Zeki (2011), Vessel (2013), and Vartanian and Skov (2014), and Amirmostofian and Mozayeni, et al., (2016).

The common theme that emerges from these works clearly point to evidence that the human brain responds to certain characteristics in visual arts, being beauty or ugliness. In that way, arts affect the human life. Berlyne (1971) noted that art has always been an instrument for beatifying life in all 3,000 cultures of the world. He thus suggested that the value of art must be measured by its effect on human life. He unequivocally submitted: "...effectiveness of a work of art invariably hinges quite subtly on how much a certain quality is present." (p. 5). For measurement of such effect, he proposed a five-point maxim for judging the quality of art. (p. 61), which has provoked many more inquiries in the field.

Berlyne in a different work (1974) noted that work of art is analyzed in informationtheoretical terms, as collection of all its elements, each of which can transmit information from four distinct sources: Semantic Information, Expressive Information, Cultural Information and Syntactic Information; together they define the characteristics and the elements of a work of art. (p. 9). Closely related, he noted, are: (1) Characteristics of an external object, (2) psychological process within the artist, (3) social norm and (4) characteristics of other elements of the same work. To him, these elements determine the value of a piece of art.

In Berlyne, et al. (1974), he referenced his earlier work, Berlyne (1967), where he connected hedonic values of paintings with fluctuation in arousal. He hypothesized that aesthetic patterns produce their hedonic effects by acting on arousal-a counterpart of the previous conviction that works of art give pleasure through their emotional impact. [p. 8]. Berlyne laid the foundation for "measuring" the aesthetic effects of a painting. That seemed to be the first step towards having a universal standard for assessing visual arts objectively. Subsequently, an urge has emerged in quest for deeper understanding of what makes an art beautiful.

Yet, for centuries, the question of what beauty is has struggled with determining an adequate definition. Some observers have sought to understand beauty in terms of the characteristics of the objects. It has been suggested that in visual art (e.g., architecture), symmetry, proportion, harmony and so on, may summarize "beauty." Ramachandran, one of the two pioneers in the field of Aesthetics, with Hirstein, identified symmetry and "balance" among ten elements (later, eight elements) present in great paintings, which 
attract people to their beauty, Ramachandran and Hirstein (1999). They presented a theory of human artistic experience related to neural mechanism. They suggested that artists either consciously or unconsciously deploy certain rules or principles (laws) to excite the visual areas of the brain. They presented many of those laws together and provided a coherent biological framework that when considered simultaneously, and viewed in a biological context, begin to make sense. They saw three bases to their argument. First, what might loosely be called the "internal logic" of the phenomenon they called laws. Second, the evolutionary rationale: the question of why the laws have evolved and have that particular form (e.g. grouping facilitates object perception). Third, the neurophysiology (e.g. grouping) occurs in extra striate areas and is facilitated by synchronization of spikes and direct limbic activation. All three of these need to be present; and must inform each other, before one can claim to have understood any complex manifestation of human nature, such as art. Many earlier discussions of art, in their view, suffer from the shortcoming of viewing the problem from just one or two of these perspectives. According to their theory of art, evaluation of an artistic object must have at least three components: (a) the logic of the art and universal rules or principles for their evaluation; (b) the evolution of the rationale; (c) and determination of the brain circuitry involved. Thus, they proposed eight laws of "artistic experience," as the key characteristics of arts.

Semir Zeki, also one of the founders of the Aesthetics (with Ramachandran), developed an outline of a theory of aesthetics that is biologically based, Zeki (1999). He considered that work an outline since he thought that the knowledge of how actually brain works was still very sketchy then. Yet, he noted, "all visual arts obeyed the law of brain and must therefore obey the laws of the brain." He said, "... art is an active process, whose function constitutes an extension of the function of the visual brain." (p. 7).

Solso [2003] connected evolution of conscious thought with the evolution of art. His basic thesis was that when humans evolved conscious awareness, they were able to make conscious association between pleasurable experiences and stimuli. That empowered people to value art.

Reber and associates (2004) asked, "what is beautiful," going back to Plato. They proposed that aesthetic experience is a function of the perceiver's processing dynamics. They noted three factors, which emerge from their literature review: goodness of the form, symmetry and figure-ground contrast, which "protypically" creates fluency in a painting. Accordingly, they suggested that these elements are at the heart of creating aesthetic pleasure.

Silvia (2005) gave a historical perspective and emphasized the importance of the modern science of "emotions," because it has much to offer the study of aesthetics, opening an expansive set of new ideas. He suggested that appraisal of theories make new predictions about emotional responses to art, expanding the domain of aesthetic emotions beyond positive emotions such as interest and enjoyment. He developed the Model of Appraisal and Interest in Art that informed the study of aesthetics. 
Silvia, et al., also proposed that spectators of paintings differ in emotional response to artwhich challenges the arousal model. Their artistic training affects their judgment. Knowledge about art affects the emotional experience of art. Emotional concepts within the Berlyne (1971) tradition, however, have emphasized affective terms such as preference, reward value, aesthetic response, hedonic response and affective response. $\mathrm{He}$ also observed that would be unproductive to lump different emotions, each with distinct causes and consequences, under one umbrella. Besides, Silva noted that according to some studies the rating of interest differs from rating of enjoyment. (p. 351). Based on these findings, he suggested an alternative Arousal Model, following in the footsteps of Berlyne, et al.

Dutton (2009) suggested an interesting and fascinating view that arts are by-products of an evolutionary adaptation, which is an instinctual trait. Therefore, arts help us to survive because they are critical to our wellbeing.

Ishizu and Zeki (2011) developed the Brain Theory of Beauty. They addressed the question that has been asked for many centuries, namely what constitutes beauty. They note that Burk (1757) suggested "Beauty is, for the greater part, some quality in bodies acting mechanically upon the human mind by the intervention of the senses." Ishizu and Zeki. (p.1). They concluded that this definition suggests presence of a consciousness of beauty that can be stimulated by any and all senses. But their reading of the relevant humanistic literature suggested that the first alternative has been more favored by those who have debated on the subject, namely that there is a single faculty of beauty into which different senses feed. Yet, they believed that alternative was echoed in Burke's definition. Overall, their research was motivated to explore how brain activity might be organized during the experience of beauty. They investigated whether beauty from different sources activated the same areas of the brain. Their data comprised 21 subjects' brain responses to stimuli (paintings and excerpts of music), using fMRI imaging. They selected three sets of stimuli- "beautiful," "indifferent" and "ugly," in each category. They concluded that there is a faculty of beauty that does not depend on modality through which it is conveyed. In their experiment, at least two sources of stimuli (and probably other sources, they note) had the same effect on their subjects. These findings led them to formulate their "brain theory of beauty." Gopnikc (2012), focused on the biological bases of human behavior. He concluded that aesthetic experiences emerge from the interaction between sensorymotor, emotions-valuation, and meaning, encompassing knowledge neural systems.

Hager and associates (2012) conducted two studies, using 193 cases in one and 147 in another, for their experimentation. They analyzed factor structure of an aesthetic experience and developed the Art Reception Survey (ARS), which is a template for assessment of characteristics of an artwork. They identified a 6 -factor structure, including recipients' cognitive involvement, positive or negative affective appraisal and creativity, and information about knowledge and comprehension about artwork for judgment of pleasure, likeability, or beauty. 
Eric Kendal, a 2000 Nobel laureate, suggested in Kendal (2012) that human brain assigns meanings of different degrees to the various shapes, colors and movement seen in a beautiful artwork. He noted, those effects illustrate that the aesthetic pleasure is not an elementary sensation (like the feeling of hot or cold, or the taste of bitter or sweet). He noted that they represent a higher-order evaluation of sensory information, processed along specialized pathways in the brain that estimate the potential for reward from work of art that people view. Kendal noted that sudden recognition of an $A H A$ moment by the viewers of art is because they suddenly see the artist's communication shared with them. They see that creative process, which characterizes every human brain, leads us to see the truth underlying both the beauty and the ugliness depicted by the artist. (E book: Loc 5019 of 9484).

Vartanian and Skov (2014) focused on the visual modality and paintings to evaluate aesthetic experience associated with exposure to works of art. They selected 15 studies through Boolean searches in Pub-Med (p. 53) to conduct a quantitative metaanalysis of $15 \mathrm{fMRI}$ studies of response to paintings. Of the fifteen studies they used, 13 had a small number of subjects, 8-21, with remaining two of larger numbers, 40 and 87 cases. Yet, Vartanian and Skov created a large sample, integrating all of those cases. They used the Activation Likelihood Estimation (ALE). They confirmed that viewing paintings engages not only systems involved in dual representation and object recognition, but also structures underlying emotions. They confirmed three hypotheses that: (1) viewing paintings activates areas in the visual cortex including "the lingual gyrus and the middle occipital gyrus, as well as the fusiform gyrus." They noted that these activations could be attributed to the processing of various features of the stimuli embedded within paintings; (2) the stimulating effect of "representations," such as landscapes, in paintings on the brain (3) the activation of the anterior insula bilaterally. The most interesting, and somewhat unexpected, result of their study was finding activation in the posterior cingulate cortex bilaterally. They noted that this region is affected when viewers "maximize the utility" of being in the "moment" (while viewing a painting), and "disconnect themselves" from their external world. Their third finding suggests that paintings may have a powerful effect on perceptive viewers' inner emotions and thoughts. The same logic suggests that paintings can have a meditative effect, as mediation defined in the Merriam-Webster dictionary.

The theoretical literature we have reviewed support a major proposition that paintings are stimuli to the human brain, and can indeed immerse the viewers in moments of pleasure when they encounter a positive aesthetic experience. This literature supports our presupposition that Abstract Romanticism has affective properties that impart positive emotional effect on viewers.

As we noted in Amirmostofian and Mozayeni, et al., along with the theoretical Aesthetics research, empirical knowledge has also moved notably on a fast trajectory in the last ten years. Recent methodology has expanded research to development of the Neuroaesthetics field by focusing on the viewers' experience with beauty and appreciation of arts at the 
levels of brain function. In this line of research, it is widely accepted that visual aesthetics, namely the capacity of assigning different degrees of beauty to certain forms, colors, or movements, is an innate human trait. The empirical research also indicates that when viewers of paintings perceive them beautiful, their brain is stimulated. Among them are: Cela-Conde (2004), Kemp and Cupchick (2007), Silvia (2007), a Joint study by Johns Hopkins Brain and Mind Center and the Walter Museum (2010), for which we have found no journal publication record, Lacey and associates (2011), Tsuklura and Gabeza (2011), Ishuzi and Zeki (2011), Vessel [2013], and Vartanian and Skov [2014].

Studies of the human brain response to the arts (e.g., visual arts) use either self-reported responses of the subjects in an experiment or directly observe subjects' brain responses to stimuli, using fMRI, albeit substantial financial and administrative cost differences. With the advent of technology, the latter has become the predominant method. We review both methodologies and address.

Cela-Conde (2004) used magnetoencephalography (MEG) on eight (8) university students to study the localization of brain areas activated during the visual perception of aesthetic objects. That research found that activation of the Prefrontal Cortex in the Human Visual Aesthetic Perception, tied the human experience (the determination of specific brain circuitry involved) points to understanding of the origin of the human response to beauty.

Silvia (2005) evaluated the modern science of "emotions" and how appraisal theories of emotion inform the study of aesthetics, making new predictions about emotional response to arts, within the Berlyne's tradition.

Kemp and Cupchik (2007) used the survey method to examine the effect of a selection of paintings on the human mind. Their data included 48 undergraduate students enrolled in a Psychology course at the University of Toronto, who received course credit for their participation. They recorded the subjects' mood before the experimentation weekly and after their viewing of a selected set of paintings. In sum, they examined the ways that the subject matter and style can predict emotional experiences of artworks, particularly when viewers' individual differences in their study were taken into account. To the best of our knowledge, this work is one of very few studies based on a survey method. Unfortunately, their very small sample size and highly specific population, hinders generalization of their results. Nonetheless, their findings are congruent with the theoretical aesthetic literature we have reviewed.

Silvia and Brown (2007) also used a survey method with similar sample limitations. Their sample included fifty-eight (58) undergraduate students. They conducted a multi-level analysis, observing anger, disgust and negative aesthetic emotion responses to artwork. They concluded that these emotions are central to individuals' appraisal of art, why people reject or embrace artworks. Their sample had the same limitations as the Kemp and Cupchick's, et al. 
On the other hand, several studies have used fMRI. These studies, in general, have a small sample due to the nature of the work involved. Therefore, their results cannot be generalized.

Lacey and associates (2011) studied the responses of eight (8) subjects to 50 paintings and observed their effect on their brains. Participants liked art images more than non-art images. They suggested that responses to one questionnaire did not necessarily influence responses to another and that these aspects of esthetic experience were independent for non-art images while, for art images, esthetic pleasure was independent of the other ratings. They corrected for the limitation of their small sample size to be able to generalize it.

Tsuklura and Gabeza (2011), based on their study of 22 subjects, successfully encoded the brain responses to stimuli (painting and excerpt of music) activity. They reached three results: (1) activity in the right orbitofrontal cortex increased (linearly) as a function of attractiveness rating; (2) activity in the left hippocampus increased as a function of subsequent memory; (3) functional connectivity between these orbitofrontal and hippocampal regions were stronger during encoding of attractive faces, leading to activation of regions associated with reward and memory. They clearly observed activation of the regions of brain associated with reward and memory and thus a positive bias toward attractive faces, and beauty in general.

Vessel (2013) used fMRI to scan the brain of sixteen (16) subjects. All of them saw the same series of 109 color artworks in a randomized manner. They investigated the differences in subjects' aesthetic responses to address the shortcomings they perceived of in previous neurasthenics research. In their opinion, those researchers "tended to utilize art pieces that were manipulated in a manner intended to have a consistent effect on observers' preferences or that were generally highly regarded and often, widely known (e.g., The Mona Lisa)." (p.2). They studied the effect of paintings that were not admiredartwork to reveal viewers' unbiased aesthetic experience. Their material included a set of two-dimensional artworks spanning over a variety of periods, regions, styles and genre from Fifteen to Twenty Centuries, Western and Eastern works, both representational and abstract genres. The artworks were original from museums. The painting categories were "beautiful, "strange," or even "ugly." They used several different analyses and created a rich data set. They noted that aesthetic experience involves not only preference, it encompasses a variety of emotional responses ranging from "beauty to awe," sublimely and in a variety of other emotions, which are often "knowledge-based." (p.3). Their results showed highly individualized responses, meaning that viewers had very little agreement. Yet, in conclusion, they noted: "Great art is, almost by definition, universal: the wide appeal it commands comes from a connection with fundamental aspect of human nature and human cognition (Kant 1790). 
Amirmostofian and Mozayeni (2016, forthcoming) used the survey method to examine the effect of a new genre of painting, created by Kamran Khavarani, known as Abstract Romanticism, on 318 subjects. They used several nonparametric estimations, which generated strong and significant statistics, which showed the effect of paintings on the subject's brain, albeit self reported, surveys.

As we noted earlier, studies of the human brain response to arts have used either selfreported responses of the subjects in an experiment or by direct observation of their brain responses to visual arts stimuli.

Yet, striking similarity emerges from studies of responses to visual arts-including paintings, whether observed in fMRI studies of subjects' brains or their self-reporting responses, as the two-phase study conducted by the Walter Museum and the Center for Mind/Brain at Johns Hopkins University, has shown, Vikan (2010), et al. Dr. Gary Vikan, the Director of the Museum then, noted, "What you'll find in this show is that there is an amazing convergence. The people who came to the museum liked and disliked the same type of shapes as the people in the lab and the people in the imaging machine. It was amazing how tight the clustering was-it was like art." [Vikan, Beauty and Brain Revealed, Dana Foundation, News and Views..., October 29, 2013].

The empirical and theoretical research reviewed, jointly provide strong support that works of art are stimuli to the brain and thus affect viewers' mood, albeit differences in details. They form the theoretical pillar of our research.

With that foundation, we evaluate what Boime, et al., observed in Khavarani's paintings. Describing one of his paintings_-Purpose 2004 [p. 185], Boime said, “.... For Khavarani this wilderness niche is far removed from the social ills that afflict the public sphere, but it offers a model of his particular destiny. One's purpose may be held in secret, while expressing itself as a healing balm for the receptive perceiver." (p.184).

We attempt to determine if the Boime's interjection stands an additional formal test we conduct in this study. We therefore test our a priori hypothesis-Khavarani's paintings calm viewers, and elevate their mood to a joyful state. Considering hundreds of worldwide affirmations, including many from patients at the Beverly Hills Cancer Center, where several of Khavarani's paintings have been on display for many years, we strive to evaluate the legitimacy of those "informal" confirmations as well.

To make this report self-contained, we have borrowed heavily from our previous paper, including our Literature Review and data description. With that background and within the context of the theoretical and empirical literature reviewed here, we present our research method and results. We verify a priori conjecture that Khavarani's 'paintings have characteristics that impart positive effect on the mind of the spectators, in this case, irrespective of subjects' age, gender and base mood. 
In the following section, we discuss our data and method, followed by a summary of our findings and discussion.

\section{Data and Methodology}

We use the data in Amirmsotifian and Mozayeni, et al. As we reported there, we collected our data during the Art Re-Store event held by the Hammer Museum and UCLA in Westwood, Los Angeles, California, November 1-30, 2013, 10:00-20:00, daily. The venue was an art district, with several galleries in close proximity to each other, one of which was Khavarani's gallery, exclusively housing his paintings. A team of trained volunteers asked the participants, if they were willing to partake in our research. If they agreed, received a written statement about the surveyor's academic background, and intended use of the data for an academic publication, as well as the expected time for answering the survey. They then received directions for visiting three galleries sequentially, and the process for recording their responses. Our questionnaire included six point scales for recording the direction and strength of variations in subjects' mood, illustrated pictorially, with a corresponding verbal description for each. The scales ranged from Sad, the lowest point, to Joyful, the highest. Subjects visited Khavarani's gallery, which exclusively housed his paintings, and two randomly selected galleries, in close proximity of his galley, on the same day. We used a Randomized Block Design (RBD) for collecting, organizing, and analyzing the subjects' responses.

We divided our data into two sets, because only 246 of the participant visited three galleries. We separated those who visited three galleries from those who only visited Khavarani's. Accordingly, 246 of the subjects, 82 each, are in each subgroup. We rotated these groups' sequential visits to create a Random Design Group. That model has three advantages. First, it controls for inter-group variations of responses and captures the between group variations. Second, it gives flexibility in experimental layouts. Third, it allows a better structure for implementation and administration of the survey.

As we reported in Amirmostofian and Mozayeni, et al., our materials included the content of the galleries subjects visited and our Survey Instrument. We include three of Khavarani's paintings here ( 2 below), which were on exhibition during our survey month. Multilayers in his paintings, particularly when subjects wore stereoscopic glasses, invoked many viewers' WOWs and/or AHA moments. 


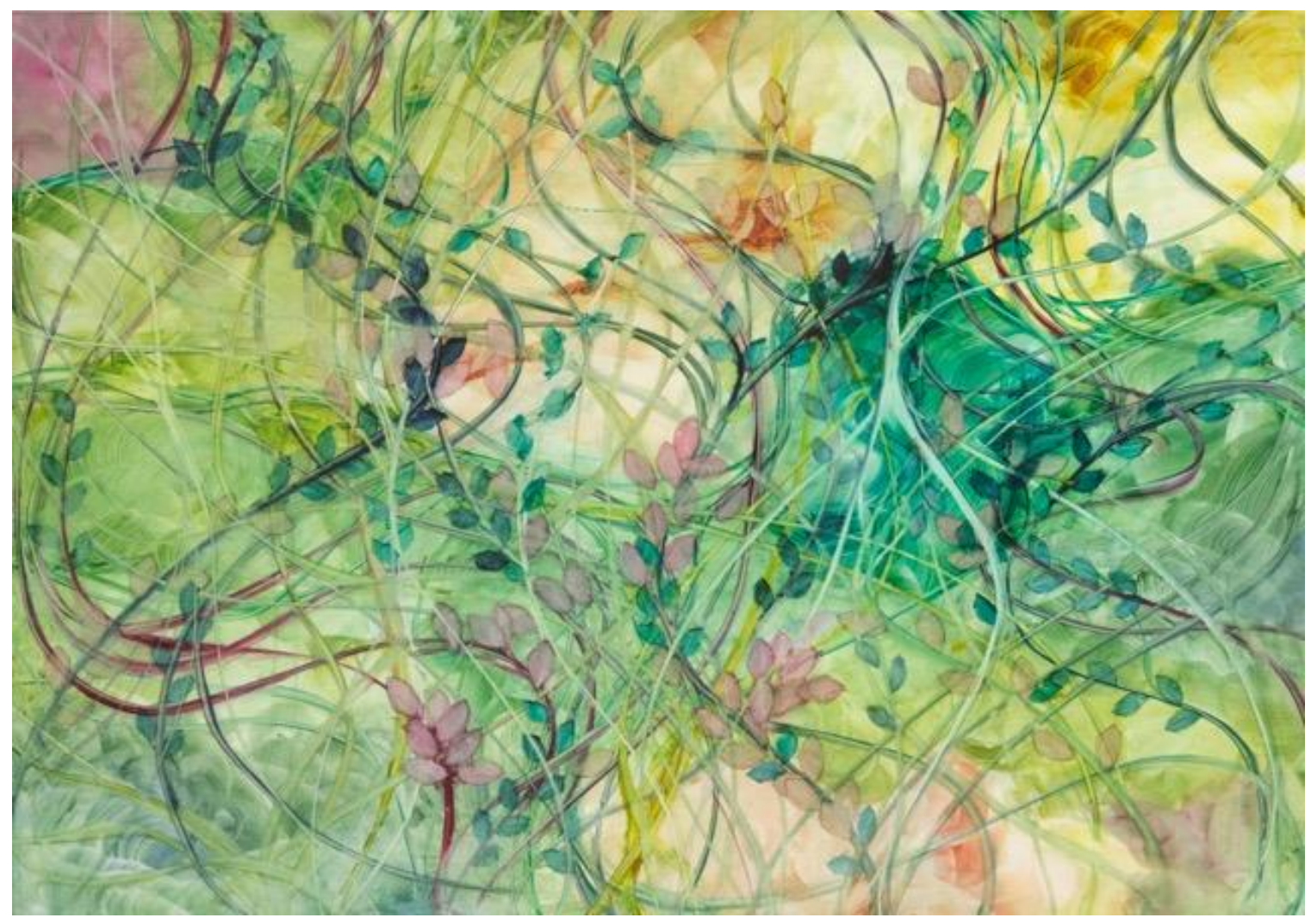

\section{L13WW Freedom}

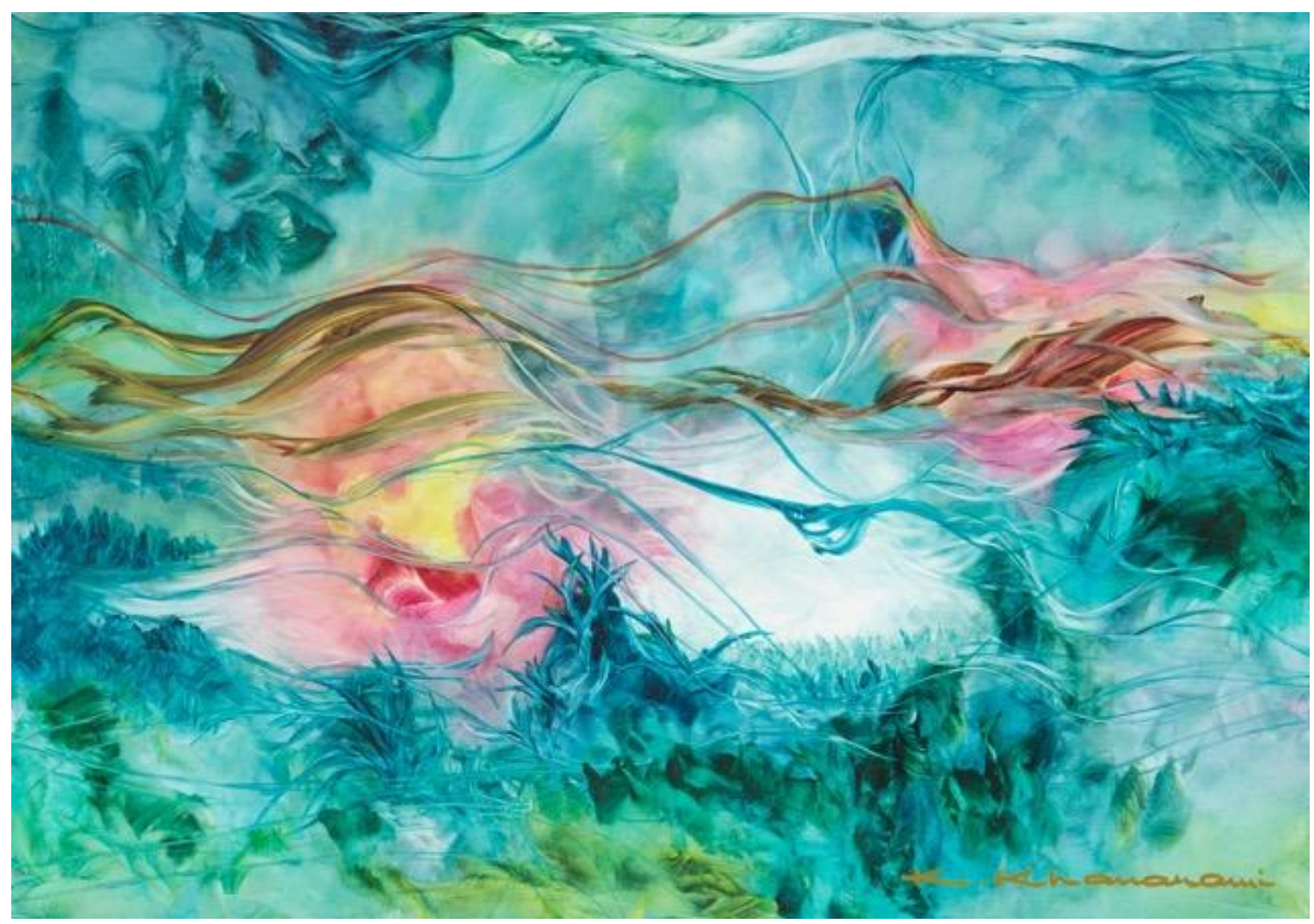




\section{L13WW_Creation}

Our survey template included six pictorial scales and their respective descriptive scales for recording participants' mood, ranging from sad to Joyful. We coded these scales in numerical interval, 0-10. As we noted above, our questionnaire included an even number of scales (six Likert scales). We excluded a mid-point scale to ensure a more accurate response by avoiding

"social desirability" bias arising from respondents' desire to please the surveyors.Garland (1991).

\section{The Model and Statistical Results}

To determine if we could use a parametric model for testing our hypothesis, we evaluated the Kernel Density Functions (KDF), and all basic statistics for all our groups and their histograms. Our data histograms showed a normal distribution for our data. Considering the large size of our sample, we expected that. With that verification, we treat our data as parametric in this study. The advantage of the parametric modes is that we can extract all the information in the data set. For statistical analyses we used the Multivariate General Linear Model (MGLM) technique. Our model has the general form,

$$
Y=\alpha+\beta_{1} X_{1}+\beta_{2} X_{2}+\beta_{3} X_{3}+\xi,
$$

where $Y$ is the dependent variable, which is the Mood After. The independent variables are the Mood Before, Gender and Age, represented by $\mathrm{X}_{1}, \mathrm{X}_{2}$ and $\mathrm{X}_{3}$, and their coefficients by $\beta_{1}, \beta_{2}$ and $\beta_{3}$, respectively. The constant term is $\alpha$, as noted in the equation, and $\xi$ represents the error term. The dependent variable measures the subjects' self-reported mood after viewing artworks (i.e., paintings) and Mood Before their mood before visiting the galleries' content. Gender is coded in integers 1 and 2, for male and female, and 3 for neutral in very few cases. Age of the subject could be recorded in seven categories: (1) 510, (2) 11-15, (3) 16-20, (4) 21-30, (5) 31-40, (6) 41-50 and (7) 51 and above. We don't have a priori expectation for the signs of the variables in the model.

As we reported in Amirmostofian and Mozayeni, et al., we have used Random Group Design (RDG) to administer and organize our data. For easy reference, we present our RDG groups and subgroups and their tagged codes in Table 1, which we borrow part of from Amirmostofian and Mozayeni. In addition to those groups, we have identified three groups in the data, which we use for more MGLM estimations. Tables 1-3 provide groups' organizational description, and their basic statistics summary. In Table 2, we have highlighted the data for Khavarani Groups. 
Table 1: Groups and Subgroups

\begin{tabular}{|c|c|c|c|}
\hline Group Code & Subgroup 1 & Subgroup 2 & Subgroup 3 \\
\hline Group A & Gal A1 & Gal AK & Gal A3 \\
\hline Group B & Gal BK & Gal B2 & Gal в3 \\
\hline Group C & Gal c1 & Gal c2 & Gal ck \\
\hline Group K_1 & Gal $A_{\kappa}$ & Gal KB & Gal Kc \\
\hline Group K-2 & Gal $A_{k}$ & Gal K $K_{B}$ & Gal $C_{k}$ \\
\hline Group K_3 & Gal KK & $x$ & $\mathrm{X}$ \\
\hline
\end{tabular}

Table 2: Basic Statistics for 12 Groups of Subjects

\begin{tabular}{|c|c|c|c|c|}
\hline \multirow{2}{*}{$\begin{array}{l}\text { Group } \\
\text { Gal } A_{1}\end{array}$} & \multicolumn{2}{|c|}{ Mean (Mood Before) } & \multicolumn{2}{|c|}{ Mean (Mood After) } \\
\hline & 5.54 & $S D=1.3$ & 5.51 & $S D=1.11$ \\
\hline Gal $A_{K}$ & 5.71 & $S D=1.28$ & 9.24 & $S D=1.28$ \\
\hline Gal $A_{3}$ & 5.65 & $S D=1.23$ & 5.63 & $S D=1.21$ \\
\hline Gal $B_{k}$ & 5.37 & $S D=1.10$ & 9.15 & $S D=1.22$ \\
\hline Gal B2 & 5.71 & $S D=1.28$ & 9.28 & $S D=1.28$ \\
\hline Gal B 3 & 5.59 & $\mathrm{SD}=1.90$ & 5.56 & $S D=1.20$ \\
\hline Gal $C_{1}$ & 8.83 & $S D=1.29$ & 6.57 & $S D=1.10$ \\
\hline Gal $C_{2}$ & 6.80 & $S D=1.10$ & 5.90 & $\mathrm{SD}=1.30$ \\
\hline Gal $C_{k}$ & 5.63 & $S D=1.70$ & 9.16 & $S D=1.32$ \\
\hline Set $K \_1$ & 6.27 & $S D=1.80$ & 9.18 & $S D=1.27$ \\
\hline
\end{tabular}




\begin{tabular}{|l|ll|ll|}
\hline Set K_2 & 5.61 & $\mathrm{SD}=1.23$ & 9.29 & $\mathrm{SD}=1.21$ \\
\hline Set K_K & 5.52 & $\mathrm{SD}=1.39$ & 9.68 & $\mathrm{SD}=0.90$ \\
\hline
\end{tabular}

Note: Decimals are rounded to the nearest two points.

Table 3: Percentage Change in Subjects' Mood for 12 Groups of Subjects

\begin{tabular}{|l|l|l|l|}
\hline Group & $\begin{array}{l}\text { Mood Before } \\
\text { Mean }\end{array}$ & $\begin{array}{l}\text { Mood After } \\
\text { Mean }\end{array}$ & $\begin{array}{l}\text { Absolute Change } \\
\text { (\% Change) }\end{array}$ \\
\hline$A_{1}$ & 5.54 & 5.51 & $-0.03(-0.005 \%)$ \\
\hline$A_{K}$ & 5.71 & 9.24 & $3.53(62 \%)$ \\
\hline$A_{3}$ & 5.66 & 5.63 & $-0.03(-.0005 \%)$ \\
\hline$B_{K}$ & 5.37 & 9.15 & $3.79(70 \%)$ \\
\hline$B_{2}$ & 5.71 & 9.28 & $3.57(52 \%)$ \\
\hline$B_{3}$ & 5.59 & 5.56 & $-0.03(-0.005 \%)$ \\
\hline$C_{1}$ & 8.83 & 6.57 & $-2.26(-25 \%)$ \\
\hline$C_{2}$ & 6.8 & 5.9 & $-0.9(-13 \%)$ \\
\hline$C_{K}$ & 5.63 & 9.16 & $3.53(63 \%)$ \\
\hline K_1 & 6.27 & 9.18 & $2.91(46 \%)$ \\
\hline K_2 & 5.61 & 9.29 & $3.68(66 \%)$ \\
\hline K_K & 5.52 & 9.68 & $4.16(75 \%)$ \\
\hline
\end{tabular}

In Table 3, we show the percentage of change in subjects' mood after visiting the three galleries in our sample. Subjects who visited Khavarani's gallery are tagged $A_{k}, B_{k}, C_{k}$ and $\mathrm{K} \_1, \mathrm{~K} \_2$ and $\mathrm{K} \_\mathrm{K}$. As we have noted earlier, Gal K_K represents the group who visited only Khavarani's gallery. Others, visited his gallery along with two others. 
We have conducted regression estimations for 12 subgroups in our data. For brevity, we report only the results for Khavarani's groups in Table 4.

Table 4: GLM Regression Results for six Khavarani Groups

\begin{tabular}{|l|l|l|l|l|}
\hline Groups & $R^{2}$ & $\begin{array}{l}\text { Mood Before } \\
\text { (Significance) }\end{array}$ & $\begin{array}{l}\text { Gender } \\
\text { (Significance) }\end{array}$ & $\begin{array}{l}\text { Age } \\
\text { (Significance) }\end{array}$ \\
\hline Gal AK & 0.04 & $\begin{array}{l}0.24 \\
(0.03)\end{array}$ & $\begin{array}{l}0.32 \\
(0.16)\end{array}$ & $\begin{array}{l}0.052 \\
(0.63)\end{array}$ \\
\hline Gal BK & 0.08 & $\begin{array}{l}0.13 \\
(0.01)\end{array}$ & $\begin{array}{l}0.02 \\
(0.93)\end{array}$ & $\begin{array}{l}-0.23 \\
(0.82)\end{array}$ \\
\hline Gal CK & 0.21 & $\begin{array}{l}0.50 \\
(0.00)\end{array}$ & $\begin{array}{l}0.33 \\
(0.19)\end{array}$ & $\begin{array}{l}-0.027 \\
(0.80)\end{array}$ \\
\hline Set K_1 & 0.11 & $\begin{array}{l}0.34 \\
(0.00)\end{array}$ & $\begin{array}{l}0.23 \\
(0.10)\end{array}$ & $\begin{array}{l}-0.002 \\
0.98\end{array}$ \\
\hline Set K_2 & 0.09 & $\begin{array}{l}0.30 \\
(0.00)\end{array}$ & $\begin{array}{l}0.17 \\
(0.15)\end{array}$ & $\begin{array}{l}0.007 \\
(0.90)\end{array}$ \\
\hline Set K_K & 0.05 & $\begin{array}{l}0.13 \\
(0.10)\end{array}$ & $\begin{array}{l}0.03 \\
(0.90)\end{array}$ \\
\hline
\end{tabular}

We have tested the collective effect of Mood Before, Gender and Age on subjects' Mood After, according to subject's self-reported survey mood after visiting the content of three galleries, one of which was Khavarani's, exclusively housing his paintings. As we report in Table 4, the Coefficient of Determination, $\mathrm{R}^{2}$, in all Khavarani cases are quite low, ranging mostly between 0.04 and 0.11 and in one case being 0.21 , in contrast to most other groups'. Furthermore, the coefficients for Mood Before, Age and Gender are negligible in all six groups reported here, albeit high significance levels for Mood After, and insignificant for Age and Gender (the desired threshold of 0.01 or 0.05 ). The Coefficient of Determinations, $\mathrm{R}^{2}$, for most other groups are above 0.80 . Our results for those groups are available upon request. With all regressions' results in hand, they suggest that the unexplained 
determinant of the model in Khavarani's cases is the effect of his paintings on the subjects' mood.

In summary, our results strongly support our main a priori conjecture both in relative and absolute comparison. We therefore, conclude with high confidence level that Khavarani's paintings unambiguously affect viewers' moods through their emotion, as if they were "maximizing the utility of the moment," being disengaged from their outside world, as Vartanian and Skov (2014) hypothesized for cases of brain scans of the subjects they studied.

\section{Conclusion}

In this research we have utilized the MGLM, a parametric model, to examine the aesthetic effect of a genre of painting known as Abstract Romanticism on individual's mental state. The results of our parametric model conforms our results from the nonparametric models of Friedman, Mann Whitney and Kruskal Willis models we reported in Amirmostofian and Mozayeni (2016, forthcoming). With results from both nonparametric and parametric model, we confirm observations by the UCLA Professor, Albert Boime, who first discovered Khavarani's new style of painting that he critiqued in The Birth of Abstract Romanticism, Art for a New Humanity, Rumi and The Paintings of Kamran Khavarani, (2008). We have tested the hypothesis that Khavarani's painting has artistic characteristics that impart positive affects on individual's mental state. Our data set includes survey of 318 (320 in the present study) randomly selected subjects. Their responses were recorded in Likert scale and numerically for our quantitative analyses. These results strongly suggest that Khavarani's paintings have a powerful effect on viewers than can be generalized to the general population. His paintings have characteristics that affect the viewers' brains and thus their psyche.

We have considered related multidisciplinary literatures. The gap in those literatures are as follows: First, we notice a heavy reliance on $\mathrm{fMRI}$ method of analysis and absence of statistical analyses of the survey of viewers for modeling the effect of paintings (or other forms of visual arts) on subjects' mind. They don't stand the litmus test for general evidence, due to their small sample size. The joint study of Johns Hopkins-Walter Art Museum survey, is a unique attempt for filling that gap. We have not, however, found a publication record for their seminal study. Second, all fMRI-based studies are comprised very small observations (generally 8-22 cases), and thus subject to the small sample bias, on the one hand. Third, our research is the first empirical study of a major book in the field of the Art History [Boime, 2008], and the very first study of the aesthetic affect of Khavarani's genre of painting, Abstract Romanticism, that became the subject of Boime's elaborate analysis. Fourth, this research opens the possibility of better understanding of the rational choice theory, in the context of Behavioral Economics. Carmerer (2003), addressing the notion of bounded rationality, proposed by Alfred Marshal. Marshal (1921). 
This research and Amirmostofian and Mozayeni (2016, forthcoming) reverberate Eric Kendal's observation in the Age of Insight, who says: "When we look at a beautiful work of art, our brain assigns different degrees of meaning to various shapes, colors, and movements we see...." [ebook, elSBN:978-1-58836-930-7, Page 5380].

Ishizu and Zeki (2011), in The Brain Theory of Beauty, explain how the human brain reacts to the beauty (or ugliness) of paintings (and music). In a different context, Zeki (1999) notes that "... Because all art obeys the laws of the visual brain, it is not uncommon for art to reveal these laws to us, often surprising us with the visually unexpected."

The method of our data collection, our statistical results generated by both the parametric and nonparametric models lend a robust support for external validation of our sample. Simply put, we propose that the 318 viewers of Khavarani's paintings in our sample are representative of the population at large.

On the light side of evidence, we have examined hundreds of testimonials from viewers of Khavarani's paintings, attesting the evocative affects of his paintings on them. Our formal results, withstanding hundreds of testaments, strongly support the hypothesis that Khavarani's paintings affect the viewer's psyche, and perhaps as Vartanian and Skav (2014) suggested, when receptive subjects view his paintings, they "maximize the utility of the moment" and "disengage" from their external world, and experience a joy similar to meditative joy. 


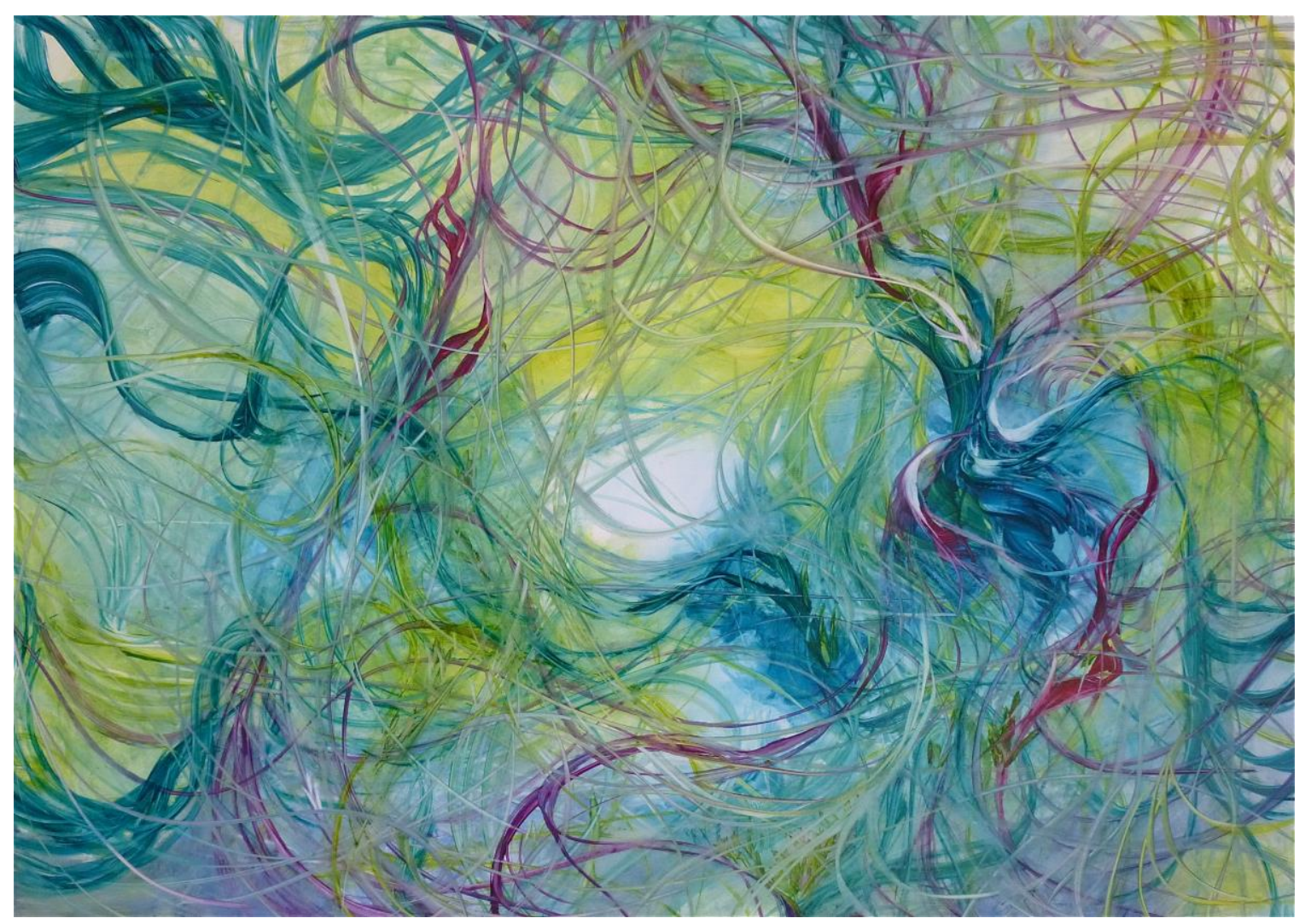

\section{L13WW_Allowance}

\section{References}

Aczel, A. D. and Sounderpandian, J. (2006). Complete Business Statistics, $6^{\text {th }}$ Edition, 2006, McGraw -Hill, Irwin Series, Operations and Decision Sciences.

Amirmostofian, P. and Mozayeni, S. (2016, forthcoming), Art for New Consciousness, Art for A New Humanity: An Empirical Investigation of Aesthetical Effect of Kamran Khavarani's Paintings, International Journal of Social Sciences, Vol. V, No. 1, 20 February 2016, forthcoming.

Anjan, C. and Vartanian, O. (2011). Neuroaesthetics, Trends in Cognitive Sciences. Vol. 18, No. 7., 370-75.

Berlyne, D. E. (1971). Aesthetics and Psychobiology, Century Psychology Series, Appleton Century-Crofts. Educational Divisions, New York.

Berlyne, D. E. (1974). The new experimental aesthetics. In D. E. Berlyne [Ed.]. Studies in the new experimental aesthetics, 1-25. Washington D.C: Hemisphere.

Boime, A. (2008 a). The Birth of Abstract Romanticism, Art for a New Humanity, Art for a New Consciousness, Rumi and the Paintings of Kamran Khavarani. Sybil City Book Company, San Francisco, CA. ISBN: 978-0-9816739-2-9, Collector's Edition.

Boime, A. (2008b, July 28). From the Desk of Albert Boime, Department of Art History, UCLA. http://albertboime.com/Letters.cfm Retrieved 11/11/2015.

Burgaso, G. (2014). http://mic.com/articles/106504/science-shows-that art-is having fantastic effects on our brains and bodies Retrieved August 1, 2015. 
Carmerer, C. F., G. Loewenstein and M. Rabin. (2003). (ed.). Advances in Behavioral Economics (The Roundtable Series in Behavioral Economics) [Print Replica] Kindle Edition.

Cela-Conde, C., and associates. (2004). Activation of the prefrontal cortex in the human visual aesthetic perception. Proceedings of the National Academy of Sciences the United States of America. 101(16), 6321- 6325 (Published online before print April 12, 2004, doi: 10.1073/pnas.0401427101.) PNAS April 20, 2004 vol. 101 no.16 6321-6325.

Cupchik, G. C. (2009). Viewing Artworks: Contributions of Cognitive Control and Perceptual Facilitation to Aesthetic Experience. Brain and Cognition, 70 (16), 84-91.

Daniel, Wayne W. (1990). "Kruskal-Wallis one way analysis of variance by ranks". Applied Nonparametric Statistics (2nd ed.). Boston: PWS-Kent. pp. 226-234 [http://psych.unl.edu/psycrs/handcomp/hckw.PDF Retrieved 11/18/15]

Danto, A. C. (1983). The Transfiguration of the Commonplace, A Philosophy of Art. Harvard University Press. Dutton, D. (2009). The art Instinct: Beauty, Pleasure and Human Evolution, Bloomsbury Press, New York.

Gopnick, B. (2012). Aesthetic science and artistic knowledge. Aesthetic Science: Connecting Minds, Brains and Experience (Shimamura, A.P. and Palmer, S.E., eds). 129-159, Oxford University Press.

Holt, J. (2013). Neurasthenics and Philosophy, SAGE Open, July-September 2013: 1-7. DOI: 10.1177/2158244013500677sgo.sagepub.com. Retrieved 8/31/15.

Hager, M., Hagman, D., Danner. D. and Schankin, A. (2012). Assessing Aesthetics Appreciation of Visual Artworks-the Construction of the Art Reception Survey (ARS), Psychology of Aesthetics, Creativity and the Arts. Vol. 6(4), Nov 2012. 320-333.

Ishizu, T., Zeki, S. (2011). Toward A Brain-Based Theory of Beauty. PLoS ONE 6(7): e21852. doi:10.1371/journal.pone.0021852. Retrieved August 2, 2015.

Kandel, E. (2012). The Age of Insight. Random House, Inc. New York. [The Age of Insight: The Quest to Understand the Unconscious in Art, Mind, and Brain, from Vienna 1900 to the Present. Kindle Edition]

Kemp, S.W.P. and Cupchik, G.C. (2007). The Emotionally Evocative Effects of Paintings. Visual Arts Research, 33 no 1, 72-82.

Lacey, S., Hagtvedt, H. van essa, M., Anderson, A., Randal, S. (2011). Art for reward's sake: Visual art recruits the ventral striatum. Neurolmage, 55.1. ProQuest Psychology Journals. Retrieved 7/30/2015.

Marshall, A. (1920). Principles of Economics (Revised ed.). London: Macmillan; reprinted by Prometheus Books. ISBN 1-57392-140-8.

Ramachandran, V.S. and Hirstein, W. (1999). The Science of Art: A Neurological Theory of Aesthetic Experience. Journal of Consciousness Studies, 6, No. 6-7,15-51.

Reber, R., Schwarz, N. and Winkielman, P. (2004). Processing Fluency and Aesthetic Pleasure: Is Beauty in the Perceiver's Processing Experience? Personality and Social Psychology Review. Vol. 8, No. 4, 364-382.

Tsikiura, T. and Cabza, R. (2011). Remembering beauty: Roles of Orbitofrontal and hippocampal regions in successful memory encoding of attractive faces, Neurolmage, 54, 1, 653-660.

Silvia, P.J. (2005). Emotional Responses to Art: From Collation and Arousal to Cognition and Emotion. Review of General Psychology. Vol. 9, No. 4, 342-357 
Silvia, P.J. and Brown, E.M. (2007). Anger, Disgust, and the Negative Aesthetic Emotions: Expanding an Appraisal Model of Aesthetic Experience, Psychology of Aesthetics, Creativity, and the Arts. Vol. 1, No. 2, 100-106.

Sklar, M. (1999). Student Problem Solving Guide for Use with Complete Business Statistics, Aczel, A., $2^{\text {nd }}$ Edition.

Vartanian, O. and Skov, M. (2014). Neural correlates of viewing paintings: Evidence from a quantitative metaanalysis of functional magnetic imaging data. Brain and Cognition, 87, 52-56.

Vessel, E., Starr, G. and Rubin, N. (2013). Art reaches within: aesthetic experience, the self and the default mode network, Frontier in Neuroscience. 7. 258.

Vikan, G. (2013). "Beauty and Brain Revealed," Dana Foundation, News and Views...,October 29, 2013.

Zaidel, D.W. (2005). Neuropsychology of Art: Neurological. Cognitive and Evolutionary Perspectives. Psychology Press, Hove, UK.

Zeki, S. (1999). Inner Vision: An Exploration of Art and the Brain. Oxford University Press, 1999. Chapters 